\title{
Research on Ash Clogging of Rotary Air Preheater in Coal-fired Power Plant
}

\author{
Zhang Boxu ${ }^{1, *}$, Li Qi ${ }^{1}$, Ding Shilong ${ }^{1}$ and Lv Bowen ${ }^{1}$ \\ ${ }^{1}$ School energy and power engineering, Wuhan university of technology, Wuhan, Hubei, 430063, China
}

\begin{abstract}
The air preheater of coal-fired units has the problem of ash blocking. Combining the working principle and ash blocking mechanism, FLUENT uses the porous media model to simulate the air preheater, and the corresponding mass flow rate at different speeds or air side inlets is obtained. The temperature results are compared and analyzed, and a reasonable air preheater is used to reduce ash clogging.
\end{abstract}

\section{Introduction}

The rapid development of social economy has led to an increase in energy demand year by year. At present, my country's energy structure is still dominated by coal. According to incomplete statistics, my country's coalfired power plants ranked first in the world in total power generation in 2019 , accounting for $50.2 \%$ of the world's total power generation by coal-fired power plants. Many power plants consider various aspects to improve power generation efficiency and reduce environmental pollution caused by coal burning. Among them, the rotary air preheater has a good effect (hereinafter referred to as the air preheater).

The air preheater has the problem of ash blocking. The serious ash blocking phenomenon increases the flow resistance, reduces the heat exchange efficiency of the air preheater, and also causes an increase in air leakage, which seriously threatens the economy and safety of the unit's operation. In the actual production process, it often happens that the air preheater has to be shut down for cleaning due to serious dust accumulation. This shows that the in-depth analysis and research on the air preheater is imminent.

\section{Analysis of ash blocking mechanism}

\subsection{Structure and working principle}

The air preheater uses a heat transfer plate to recover the heat in the high-temperature flue gas. Through the rotation of the central rotor, the heat is brought to the low-temperature air area and transferred to the air to achieve the purpose of recovering the flue gas heat and increasing the temperature of the incoming air. This greatly reduces environmental pollution and improves boiler efficiency. The flue gas and air of the air preheater are usually arranged in a countercurrent manner, that is, the direction of the flue gas flow through the air preheater is opposite to the direction of the air flowing through the air preheater, and the rotor speed is generally relatively low, which facilitates the sufficient heat exchange process. get on. The air pre-device structure is shown in Figure 1.

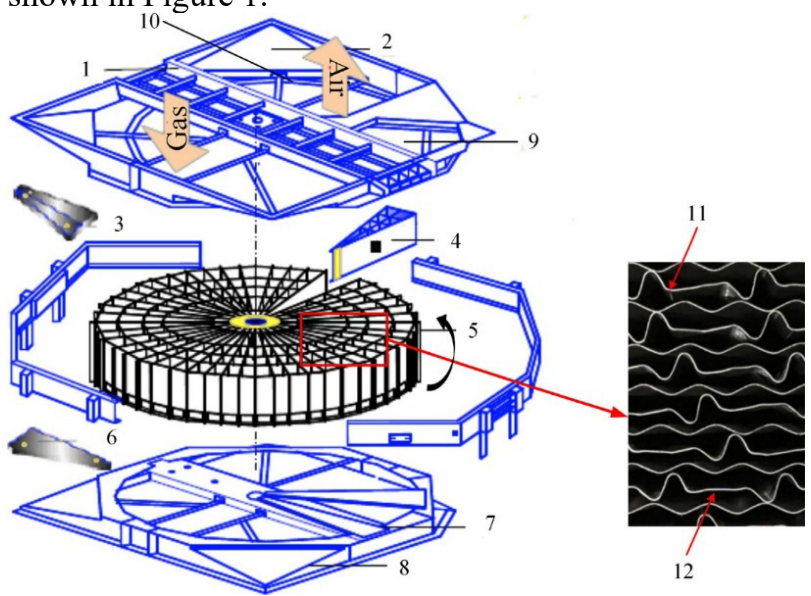

(1. Upper beam; 2. Upper gas channel; 3. Hot end sector seal; 4. Segmented steel plate; 5 . Corrugated plate; 6 . Cold end sector seal; 7. Lower beam 8 . Bottom flue gas channel; 9. One time Air outlet; 10. Secondary air outlet; 11. Corrugated board; 12. Positioning board)

Fig. 1. The working principle and structure of air preheater

\subsection{Ash blocking mechanism}

First of all, the air preheater on the structure is easy to accumulate and block up. Its rotor is composed of a large number of heat transfer elements closely arranged. The heat transfer elements are often very thin metal plates, and the gap between the plates is very small. At the same time, in terms of sediment, due to the relatively low temperature at the cold end of the air preheater, sulfuric acid and ammonium bisulfate vapors are prone to condense here, resulting in fouling and clogging.

Ammonium bisulfate blockage: Ammonium bisulfate is a highly viscous liquid substance in the temperature range of $150-220^{\circ} \mathrm{C}$, which is easy to stick. In coal-fired

*Corresponding author's e-mail: zhangboxu@whut.edu.cn 
power plant units with SCR denitration systems, the escaped ammonia can easily react with sulfur oxides in the flue gas to form ammonium bisulfate, which will block the air preheater.

Cold end low-temperature acid corrosion: The cold end temperature of the air preheater is low, and the sulfuric acid vapor in the flue gas is attached to the heat transfer element, causing acid corrosion at the cold end of the air preheater, which intensifies the dust accumulation and blockage of the air preheater.

\section{Air preheater model establishment}

Taking the three-division silo rotary air preheater of a $310 \mathrm{MW}$ coal-fired power plant as the research object, the geometric model of the air preheater is established based on the actual situation, and the FLUENT software is imported for analysis and solution. The actual air preheater model is more complicated, including components such as beam structures that have less effect on heat transfer. These components are omitted in the modeling to simplify the calculation. The simplified model is roughly composed of a central cylindrical rotor and three corresponding upper and lower fan-shaped flow channels. The geometric parameters are set according to the actual geometric parameters of the air preheater. Based on the fact that the air preheater rotor is composed of densely arranged heat storage plates, there is only a small gap between which there is fluid passing.

At the same time, in order to ensure the heat transfer efficiency, the heat storage plate has ripples, so it is extremely complicated to calculate the heat transfer problem of the air preheater. Big. Through the analysis of the structure of the air preheater, the metal plate divides the rotor into a large number of narrow semienclosed spaces, and the fluid passes through these porelike structures to complete heat exchange, which is just in line with the characteristics of the porous medium model. According to formula, it can be calculated that the flow Reynolds number of porous media is about 2500-6000.

When the cold-end and hot-end fluids continuously pass through the workpiece in opposite directions, the local thermal equilibrium assumption of the porous media model cannot be satisfied. Therefore, the twoelement non-equilibrium thermal model should be used, which can obtain more accurate results than the application of the local thermal equilibrium model. The specific method is to apply different energy equations to describe the heat transfer problems in the solid term and the fluid term respectively.

The actual parameter setting of the analog parameter data of the air preheater. Under normal working conditions, the inlet temperature of the primary and secondary air at the cold end is similar to the atmospheric temperature, and the inlet temperature at the flue gas side at the hot end is about $390^{\circ} \mathrm{C}$. The specific physical and material parameters of the air preheater are shown in Table 1 and Table 2.
Table 1. Operating parameter table of rotary air preheater for three-division warehouse

\begin{tabular}{|c|c|}
\hline $\begin{array}{c}\text { Operating } \\
\text { parameters }\end{array}$ & Numerical value \\
\hline Air preheater speed & $1.14 \mathrm{r} / \mathrm{min}$ \\
\hline $\begin{array}{c}\text { Flue gas inlet } \\
\text { temperature }\end{array}$ & $668 \mathrm{~K}$ \\
\hline $\begin{array}{c}\text { High temperature } \\
\text { primary air inlet } \\
\text { temperature }\end{array}$ & $293 \mathrm{~K}$ \\
\hline $\begin{array}{c}\text { High temperature } \\
\text { secondary air inlet } \\
\text { temperature }\end{array}$ & $293 \mathrm{~K}$ \\
\hline $\begin{array}{c}\text { Flue gas mass flow } \\
\text { High temperature } \\
\text { primary air mass } \\
\text { flow }\end{array}$ & $1384090 \mathrm{~kg} / \mathrm{h}$ \\
\hline
\end{tabular}

Table 2. Physical parameters of heat transfer element

\begin{tabular}{|c|c|c|c|}
\hline Hot end & DU & Cold end & $\mathrm{NF}$ \\
\hline material & SPCC & material & $\begin{array}{l}\text { Corrosion } \\
\text { resistant steel }\end{array}$ \\
\hline Void ratio & 0.926 & Void ratio & 0.862 \\
\hline $\begin{array}{l}\text { Heat transfer } \\
\text { original } \\
\text { thickness }\end{array}$ & $0.5 \mathrm{~mm}$ & $\begin{array}{l}\text { Heat transfer } \\
\text { original } \\
\text { thickness }\end{array}$ & $0.75 \mathrm{~mm}$ \\
\hline $\begin{array}{c}\text { Interface area } \\
\text { density }\end{array}$ & $\begin{array}{c}373.0 \mathrm{~m} 2 \\
/ \mathrm{m} 3\end{array}$ & $\begin{array}{c}\text { Interface area } \\
\text { density }\end{array}$ & $330.8 \mathrm{~m} 2 / \mathrm{m} 3$ \\
\hline
\end{tabular}

When the number of grids is 312,984 , the grid independence can be proved. The specific meshing situation is shown in Figure 2.

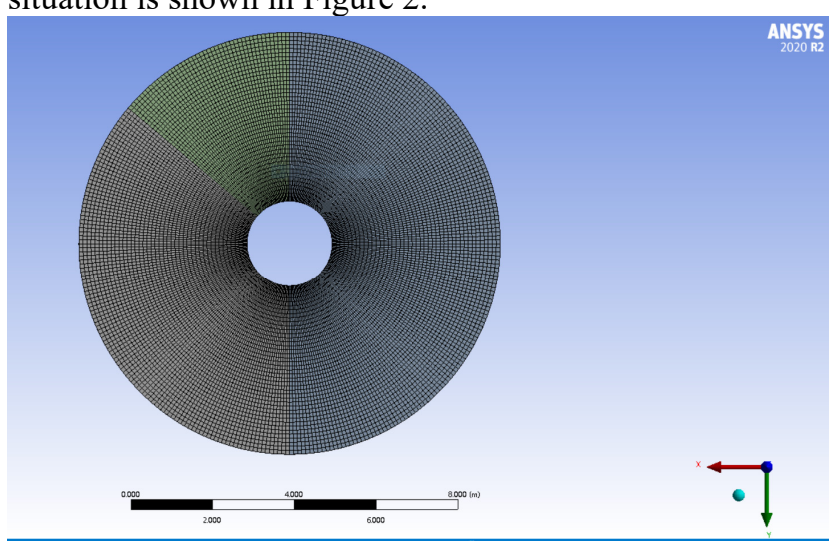

Fig. 2. Schematic diagram of grid division of air pre-heater

\section{Results and analysis}

\subsection{Simulation of basic conditions analysis}

The average temperature of the cold end is around $410 \mathrm{~K}$, and the flue gas outlet temperature gradually increases along the direction of rotation. It can be seen from the figure that the temperature of the primary air inlet at the cold end is slightly greater than that of the secondary air inlet. However, since the gap between them is very small, they can be approximately regarded as equal. At the same time, it can also be found that the temperature 
distribution trend of the cold end is also similar to the temperature distribution trend of the cold end. The average temperature of the hot end is around $620 \mathrm{~K}$. It can also be seen that the temperature distribution of the hot end is similar to that of the cold end through the hot end temperature distribution graph.

In engineering, combined with the actual working conditions of the SCR denitrification system, it is usually specified that the formation temperature of $\mathrm{ABS}$ in the rotary air preheater is $190^{\circ} \mathrm{C}$. The condensation temperature of $\mathrm{ABS}$ is about $145^{\circ} \mathrm{C}$, so it can be determined that the deposition temperature range of $\mathrm{ABS}$ is between $140^{\circ} \mathrm{C}$ and $190^{\circ} \mathrm{C}$. Therefore, according to the temperature distribution map, the area where the serious fouling and clogging phenomenon occurs and the reason can be analyzed. The most serious area of ABS deposition is at the junction of the hot end and the cold end.
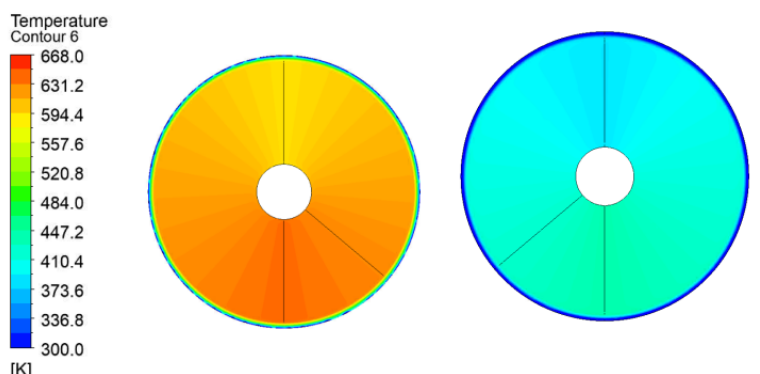

Fig. 3. Temperature distribution diagram of the hot end and the hot end of the air preheater

\subsection{The influence of air inlet mass flow}

Due to frequent changes in operating conditions during boiler operation, the influence of mass flow on RAPH cannot be ignored. As the mass flow decreases, the efficiency of the preheater increases. As shown in Figure 4 , it can be seen that as the mass flow increases, the pressure drop increases significantly.
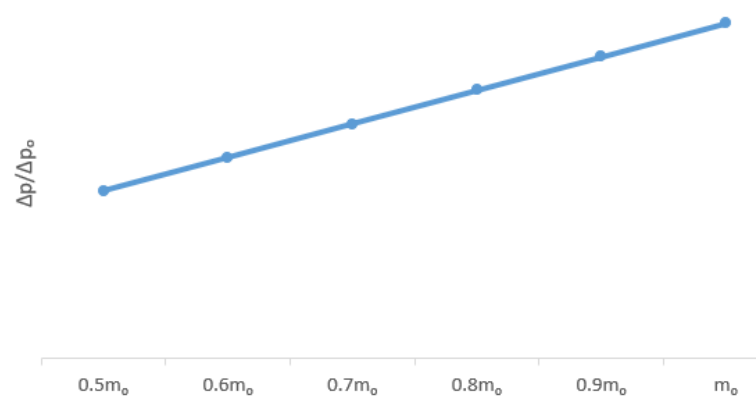

Fig. 4. The influence of mass flow on pressure drop of preheater

Calculate the loss according to $\mathrm{W}=\mathrm{V} \cdot \mathrm{N} \cdot \mathrm{q}(\mathrm{V}$ is the volume, $\mathrm{n}$ is the speed, and $\mathrm{q}$ is the flow rate). As the mass flow rate decreases, the delay temperature decreases. Because of the nature of the fluid, the flue gas will become denser. Therefore, when the air preheater is in operation, the residual flue gas is serious. Especially under the condition of high speed, the loss will increase sharply.
Cold-end corrosion and ABS deposition are basically not affected by the mass flow rate. Although it can be seen that the two areas have decreased, the heat transfer between the phases increases, and the heat transfer element can absorb more heat from the flue gas. Finally, the area of the substrate decreases at low temperatures.

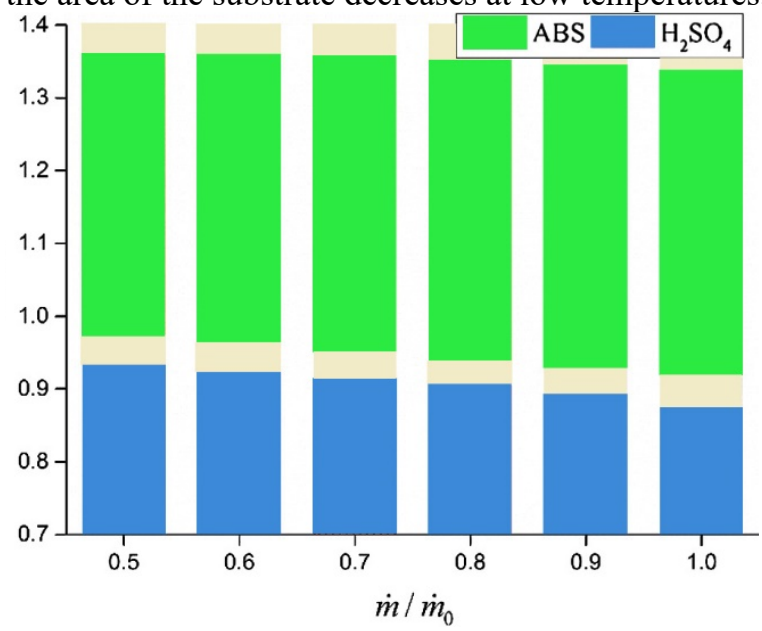

Fig. 5. The influence of mass flow rate on cold end corrosion and $\mathrm{ABS}$ deposition distribution

\subsection{Influence of rotor speed}

The influence of the rotation speed on the air preheater is obvious. According to the continuous increase of the rotation speed as shown in Figure 6, the efficiency increases. The heat that can be absorbed by the heat transfer plate increases, the pressure loss decreases, and when the speed reaches the interval near the predicted value, the air preheater operates stably.

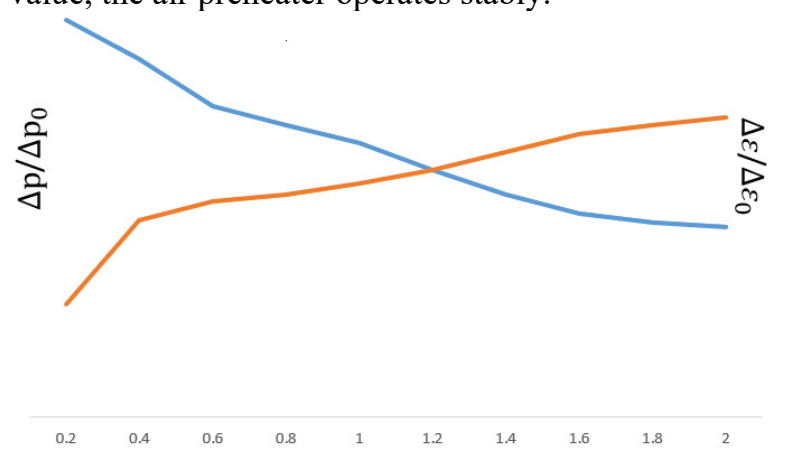

Fig.6. The effect of speed on the efficiency and pressure drop of the preheater

As the speed increases, the efficiency increases significantly. Regarding pressure loss, as the rotational speed increases, more heat can be absorbed from the flue gas by the heat transfer element. The pressure loss is slightly reduced, which may be due to the decrease in fluid viscosity and increase in density as the flue gas temperature decreases. Figure 7 shows the influence of rotor speed on cold end corrosion and ABS deposition distribution. The speed of rotation continues to increase, the heat transfer efficiency of the air preheater continues to increase, and the cold end corrosion and ABS deposition position increase. On the contrary, the speed is reduced, the flue gas does not have enough 
temperature drop, the temperature of the heat transfer elements in the whole mechanism rises, the cold end corrosion and the ABS deposition are weakened, and the power plant occasionally reduces the speed and supplements the soot blower to achieve the purpose of cleaning the air preheater. The outlet temperature at different speeds is shown in Table 3 .

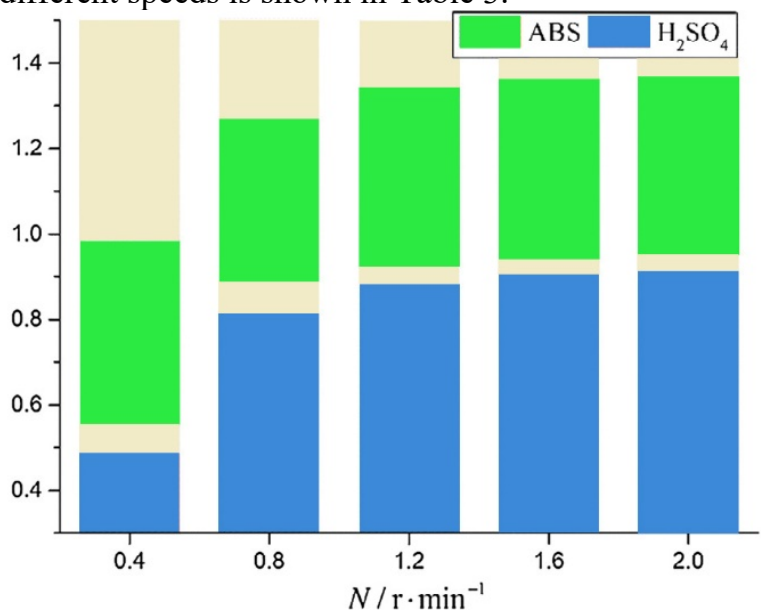

Fig. 7. Effect of Rotor Speed on Cold End Corrosion and ABS Deposit Distribution

Table 3. Outlet temperature/K under different speed conditions

\begin{tabular}{|cccccc|}
\hline Rotating speed & 0.34 & 0.74 & 1.14 & 1.54 & 1.94 \\
\hline $\begin{array}{c}\text { Primary air outlet } \\
\text { temperature }\end{array}$ & 554.27 & 525.02 & 525 & 521 & 518 \\
$\begin{array}{c}\text { Secondary air outlet } \\
\text { temperature }\end{array}$ & 454.49 & 471.69 & 471 & 473 & 473 \\
$\begin{array}{c}\text { Outlet temperature } \\
\text { of flue gas channel }\end{array}$ & 496.41 & 488.99 & 488 & 488 & 488 \\
\hline
\end{tabular}

\section{Conclusion}

By using the porous medium model in FLUENT, the air preheater model is processed, and the operating conditions of flue gas and air in the machine are simulated. The temperature distribution, sulfuric acid corrosion and ABS deposition are described. For the transformation, we can design by reducing the inlet temperature, increasing the speed and reducing the mass flow of the inlet air.

\section{Acknowledgement}

Financially supported by self-determined and innovative research funds of WUT+2020-ND-B1-11

\section{References}

1. Zhu Xiaoyi. Discussion and application of antifouling technology for rotary air preheater of 600 MW unit. Electric Power System Equipment, 2019, (17): 144-145.

2. Qu Yuejin. Analysis on the technical transformation of air preheater for preventing ash clogging. Shanxi Science and Technology, 2019, 34(4): 128-130,135.
3. Zou Xueming, Wang Lin, Ding Liang. Research on anti-blocking technology of air preheater based on circulating air. Energy-saving technology, 2018, 36(4): 341-346.

4. Wang Chengliang. Research on anti-blocking technology of boiler rotary air preheater. Huadian Technology, 2015, (3): 18-21.

5. Li Peng, Xu Huiling, Wang Yongge. Research on ash blocking treatment technology of air preheater of coal-fired thermal power unit. Electromechanical Information, 2019, (24): 92-93,95.

6. Jiang Baomi. Discussion on air volume slitting and anti-blocking technology of $1000 \mathrm{MW}$ boiler air preheater. Electric Power Construction, 2019, (20): 53-54.

7. Cai Mingkun. Analysis of the influence of setting circulating air on the performance and ash blocking of the rotary air preheater. Boiler Technology, 2018, 49(6): 18-26.

8. Li Chao. On-line monitoring of ash blocking in air preheater after denitration. Master's degree thesis, North China Electric Power University (Beijing), 2017.

9. Liu Haixiao. Research on the countermeasures against the blockage of the air preheater caused by ammonium bisulfate. Master's degree thesis, North China Electric Power University (Beijing), 2017.

10. Sun Jian. Optimization and transformation of rotary air preheater in thermal power plant. Master's degree thesis, North China Electric Power University (Beijing), 2015.

11. Zhang Lei. Research on Thermal Calculation Model of Rotary Air Preheater in Four-division Warehouse. Master's Degree Thesis, North China Electric Power University (Baoding), 2017.

12. Sun Dening. Research on efficiency improvement of power station rotary air preheater. Master's degree thesis, Southeast University, 2004.

13. Yang Xiangzhao. Experimental and numerical simulation of the characteristics of the cold end heat transfer element of the air preheater. Master's degree thesis, North China Electric Power University (Baoding), 2016.

14. Gu Xingpeng. Numerical simulation and experimental research on heat transfer and flow of enamel heat storage element of rotary air preheater. Master's degree thesis, North China Electric Power University (Baoding), 2015.

15. Zhou Zufang. Research and transformation of air preheater for large-scale power station boilers. Master's degree thesis, Dalian University of Technology, 2008.

16. Heng Chen, Peiyuan Pan, Huaishuang Shao, Yungang Wang, Qinxin Zhao. Corrosion and viscous ash deposition of a rotary air preheater in a coal-fired power plant. Applied Thermal Engineering, 2017, 113: 373-385. 